\title{
Clinical relevance of IgE-antibodies to PR-10 proteins in patients with syndrome of oral allergy
}

\author{
E Bass, ${ }^{*}$ M Mokronosova \\ From Food Allergy and Anaphylaxis Meeting (FAAM 2013) \\ Nice, France. 7-9 February 2013
}

\begin{abstract}
Background
A considerable number of pollen-allergic patients develops allergy to plant foods, which has been attributed to crossreactivity between food and pollen allergens belongs to PR-10 proteins. The majority of these patients refuse from take the foods containing PR-10 explaining bad taste or sense of itch in the mouth - syndrome of oral allergy (SOA). It is assumed that the primary is sensitization to pollen origin PR-10 proteins and induction of the IgE-aB to the fruit \& vegetable origin PR-10 is secondary. The aim of the study: to measure the IgE-aB to PR-10 proteins in patients with SOA.
\end{abstract}

\section{Methods}

There were 21 patients (pts) with SOA (12 male/9 female, age $1-42$ years) were observed. From them 18 was suffered from pollen allergy. Component-resolved diagnosis was provided by ImmunoCap ISAC (ThermoFisher Scientific, Sweden) with all 21 sera of observed pts.

\section{Results}

$18 / 21$ of pts had positive levels of specific IgE-aB to pollen PR-10 allergens ( $r A l n g$, rBet $\mathrm{v} 1$ and rCor a 1.0101). The levels of specific IgE-aB to $\mathrm{rBet} v 1$ were positive in $17 / 21$ pts (81\%); to rAln g 1 in $12 / 21(57,1 \%)$; to rCor a 1.0101 in $8 / 21(38,1 \%)$. There were $17 / 21$ pts who had specific IgE-aB both to pollen and to the food allergens. The levels of specific IgE-aB to the apple (rMal d 1) were positive in $17 / 21$ cases ( $81 \%)$; to peach (rPru p 1 ) and peanut (rAra h 8 ) in 13/21 (69\%); to hazelnut (rCor a 1.0401) and soybeans (rGly m 4) in 11/21 (52,4\%); to the carrot (rDau c 1 ) and celery (rApi g 1 ) in $3 / 21$ (14,3\%) cases; to rAct $d 8$ (kiwi) were positive $2 / 21$ (9,5\%) of pts. The SOA to such fruits as apple, peach and hazelnut is often in pts with SOA. Clinical manifestation of allergy to peanut and

Mechnikov's Research Institute for Vaccines and Sera, Moscow, Russian Federation

C) Biomed Central soybeans are rarer. There were IgE-aB only to the plant food PR-10 proteins but not to the pollen in $3 / 21$ samples of sera $(14,3 \%)$. One of these pts had specific IgE-aB only to rMal d 1 (apple), one - to rAra h 8 (peanut), and one was sensitized to the apple, hazelnut and soybeans.

\section{Conclusion}

The sensitization to PR-10 protein is followed by primary immune response to tree's pollen, predominantly rBet $\mathrm{v} 1$. But in some cases the primary sensitization to PR-10 was realized to plant foods. The SOA develops in sensitized patients after eating nuts, fruits and vegetables (except peanuts and soybeans) containing PR-10 proteins.

\section{Disclosure of interest}

None declared.

Published: 25 July 2013

doi:10.1186/2045-7022-3-S3-P90

Cite this article as: Bass and Mokronosova: Clinical relevance of IgE-antibodies to PR-10 proteins in patients with syndrome of oral allergy. Clinical and Translational Allergy 2013 3(Suppl 3):P90.

Submit your next manuscript to BioMed Central and take full advantage of:

- Convenient online submission

- Thorough peer review

- No space constraints or color figure charges

- Immediate publication on acceptance

- Inclusion in PubMed, CAS, Scopus and Google Scholar

- Research which is freely available for redistribution 